\title{
A Canadian Perspective on the Management of Irritable Bowel Syndrome
}

\author{
Stephen M Collins MBBS FRCPUK FRCPC
}

\begin{abstract}
$\mathrm{A}_{\mathrm{B}}$ Canadian Perspective on the Management of Irritable Bowel Syndrome addresses aspects of irritable bowel syndrome (IBS) that are current and changing. Although it is well recognized that this syndrome is common, its precise prevalence is poorly understood, and the biological distinction between those who seek health care and those who do not is unclear. Dr Charles Bernstein (pages 5B-7B), in his presentation, describes factors that may precipitate IBS, including infectious gastroenteritis. There is a growing awareness of the link between traveller's diarrhea or food poisoning and the development of a chronic symptom complex indistinguishable from IBS. Just as Dr Bernstein points out, this association is a hazard for individuals who may have been previously healthy but travel extensively to endemic countries.

During this symposium, attention was drawn to the increased understanding of mechanisms of symptom generation in IBS. Traditionally, this has been considered a motility disorder, but over the years 'motility drugs' have failed to provide the expected global relief of symptoms. Subsequently, attention turned to other mechanisms, and now much emphasis is placed on the role of sensitized sensory nerves as a basis for subjective symptoms of bloating and abdominal pain, as well as the changes in motility. The gut is the largest 5 -hydroxytryptamine (5-HT)-containing organ in the body, and following the identification of its crucial role in migraine, attention has turned to the role of
\end{abstract}

5-HT in IBS. It is believed that 5-HT may sensitize sensory nerves and alter motility. New generations of 5-HT agonists and antagonists are becoming available and provide much potential for the treatment of IBS.

The socioeconomic impact of IBS is also discussed in this symposium. It has generally been felt that, although this is not a disease that is associated with any mortality, morbidity can be substantial in severe cases. In addition, this attention-seeking behaviour exhibited by some patients with IBS drives health care costs. The majority of the socioeconomic burden is through indirect costs including absenteeism from work or school. Dr Michel Boivin (pages $8 \mathrm{~B}-11 \mathrm{~B}$ ) provides an overview of the socioeconomic impact of IBS in Canada. This impact is substantial both in terms of cost and impaired quality of life. It is similar in magnitude to that described for IBS in other Western countries.

As our understanding of IBS increases, so will the number of new therapies. Dr Gervais Tougas (pages 12B-13B), in his section of the symposium, outlines directions in which scientists in academic and pharmaceutical centres are working toward developing new treatments. In addition to 5-HT, there is interest in antagonists for neurokinin and opioid receptors.

It is clear that we are on the verge of a new era in terms of the understanding and ability to treat this common yet troublesome condition. 


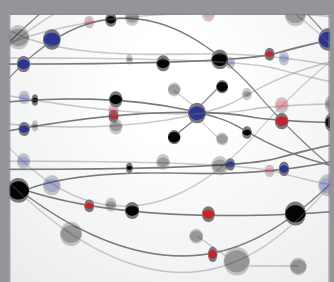

The Scientific World Journal
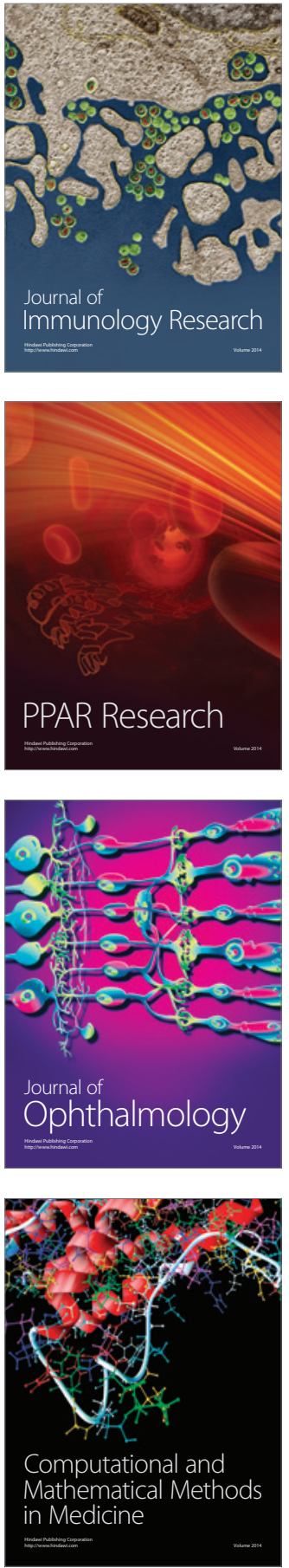

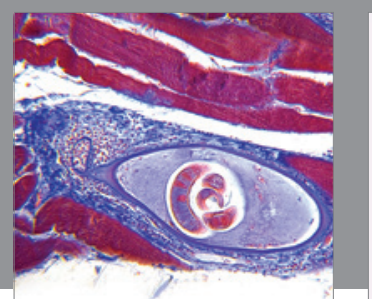

Gastroenterology Research and Practice

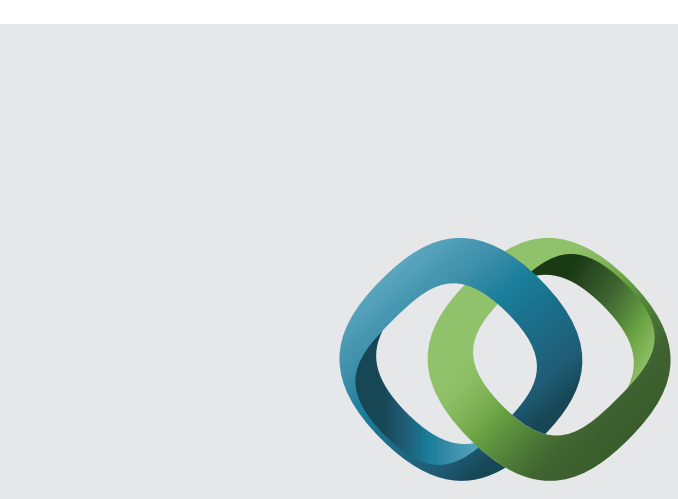

\section{Hindawi}

Submit your manuscripts at

http://www.hindawi.com
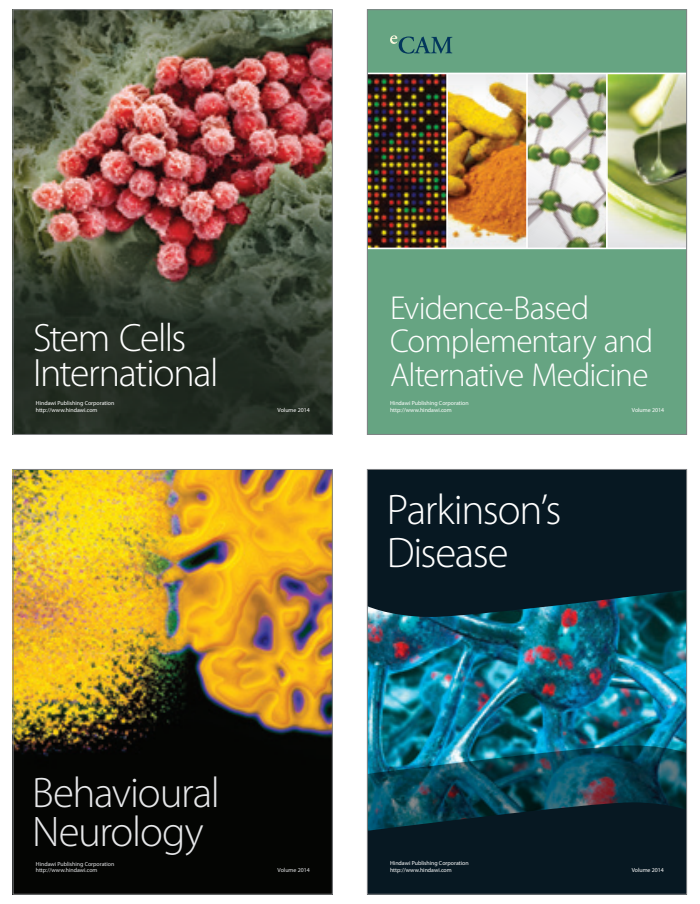
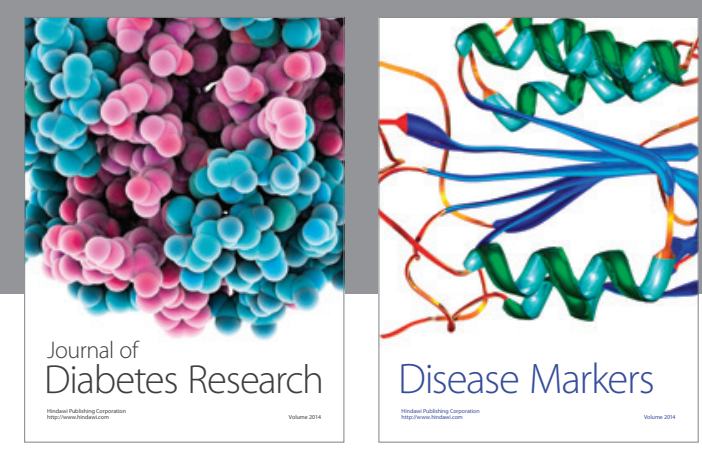

Disease Markers
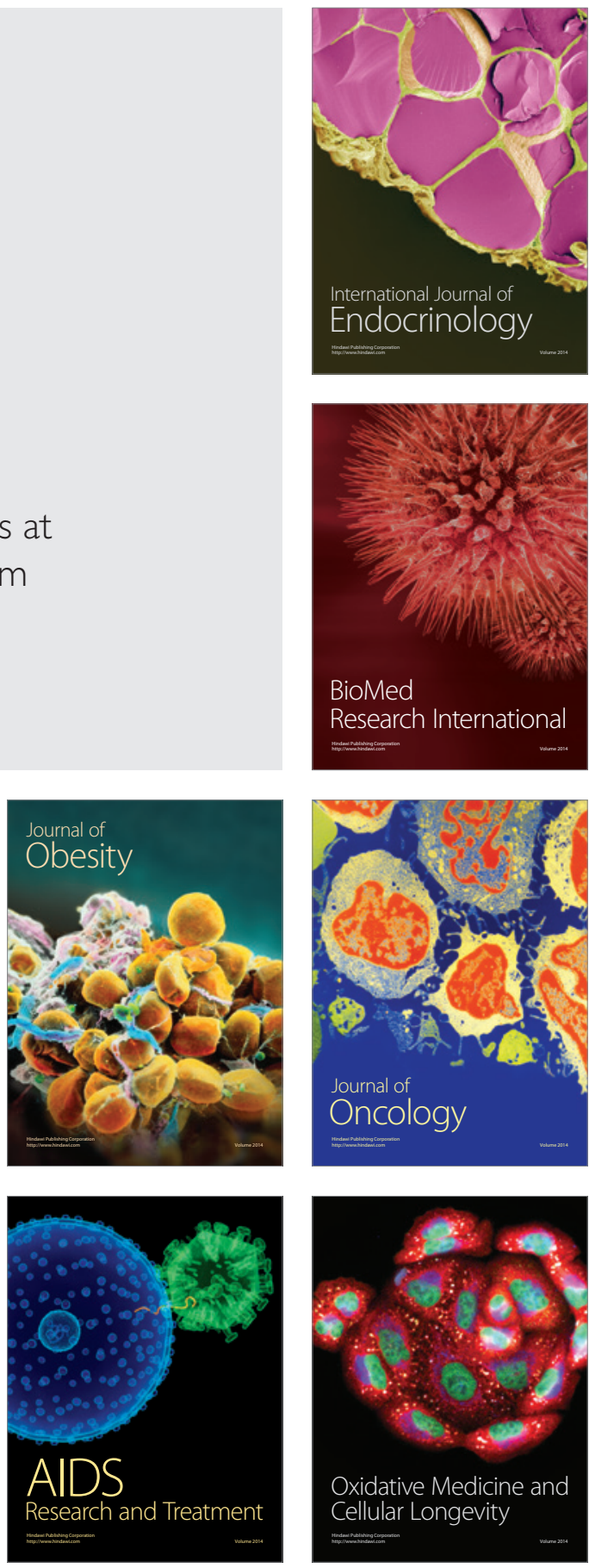